\title{
Effects of Annealing on Magnetic Properties of New Ferromagnetic Semiconductor (In, Al, Mn)As
}

\author{
Y. F. Chen ${ }^{1}$, W. N. Lee ${ }^{2,3}$, J. H. Huang ${ }^{1,2}$, T. S. Chin ${ }^{1}$, X. J. Guo ${ }^{4}$, and H. C. Ku ${ }^{5}$ \\ ${ }^{1}$ Department of Materials Science and Engineering, National Tsing Hua University, Hsinchu 300, Taiwan, R.O.C. \\ ${ }^{2}$ Materials Science Center, National Tsing Hua University, Hsinchu 300, Taiwan, R.O.C. \\ ${ }^{3}$ Department of Materials Science and Engineering, National Chiao Tung University, Hsinchu 300, Taiwan, R.O.C. \\ ${ }^{4}$ Institute of Physics, Academia Sinica, Taipei 11529, Taiwan, R.O.C. \\ ${ }^{5}$ Department of Physics, National Tsing Hua University, Hsinchu 300, Taiwan, R.O.C.
}

\begin{abstract}
The effects of low-temperature $\left(210{ }^{\circ} \mathrm{C}-290{ }^{\circ} \mathrm{C}\right)$ annealing on the microstructure, lattice constant, and magnetic properties of $\left(\mathrm{In}_{0.52} \mathrm{Al}_{0.48}\right)_{0.91} \mathrm{Mn}_{0.09} \mathrm{As}$ grown by low-temperature molecular-beam epitaxy were studied. The results show that low-temperature annealing has little influence on the crystalline structure and interface quality of $\left(\mathrm{In}_{0.52} \mathrm{Al}_{0.48}\right)_{0.91} \mathrm{Mn}_{0.09} \mathrm{As}$ epilayer. In contrast, both the lattice constant and Curie temperature of $\left(\mathrm{In}_{0.52} \mathrm{Al}_{0.48}\right)_{0.91} \mathrm{Mn}_{0.09} \mathrm{As}$ are found to be strongly dependent on the annealing temperature. The lattice constant linearly decreases with increasing annealing temperature; while the Curie temperature increases with increasing annealing temperature up to $250{ }^{\circ} \mathrm{C}$, and then abruptly decreases upon further annealed at $270 \circ \mathrm{C}$ and $290{ }^{\circ} \mathrm{C}$.
\end{abstract}

Index Terms-Diluted magnetic semiconductor, (In, Al, Mn)As, spintronics, low-temperature annealing, magnetic properties.

\section{INTRODUCTION}

$\mathbf{F}$ ERROMAGNETIC III-V diluted magnetic semiconductor (DMS) has been actively studied in recent years, due to its significance in basic physics and potential applications to spintronics devices [1], [16], [2], [3], [17], [4], [5]. The hole-mediated ferromagnetism [5] in III-V DMS is sensitive to both the electronic and less understood structural properties of the metastable alloy, and therefore searching for and/or developing new DMS is important [6], [7]. New quaternary diluted magnetic semiconductors, such as (In, Ga, Mn)As and (In, Al, Mn)As, grown on InP substrates is important for investigating spin transport effects in devices built on InP. Moreover, such quaternary ferromagnetic semiconductors have many potential advantages that cannot be realized by ternary alloy magnetic semiconductors [8]. Recently, several groups had demonstrated the growth and magnetic properties of quaternary (In, Ga, Mn)As [7]-[10], and very good progress had been made; for example, the Curie temperatures of 100 $\mathrm{K}-130 \mathrm{~K}$ had been reported in (In, Ga) $)_{1-x} \mathrm{Mn}_{x}$ As with $x$ higher than $10 \%$ [7], [9], [10]. In this work, we initiated the study of another quaternary DMS, ( In, Al, Mn)As, and have successfully grown $\left(\mathrm{In}_{0.52} \mathrm{Al}_{0.48}\right)_{0.91} \mathrm{Mn}_{0.09} \mathrm{As}$ on InP substrates. The effect of low-temperature annealing on the lattice constant and magnetic properties of ternary $(\mathrm{Ga}, \mathrm{Mn})$ As grown on GaAs has been intensely studied [11]-[15]. Here, we report the effects of low-temperature annealing on the microstructure, lattice constant and magnetic properties of this new quaternary $\left(\mathrm{In}_{0.52} \mathrm{Al}_{0.48}\right)_{0.91} \mathrm{Mn}_{0.09} \mathrm{As}$ DMS.

\section{EXPERIMENTAL PROCEDURE}

The samples used in this study were grown on (001) semi-insulating, epi-ready InP substrates by a Varian Modular GEN-II

Digital Object Identifier 10.1109/TMAG.2005.854687
MBE system, with an $\mathrm{As}_{4} / \mathrm{III}$ beam equivalent pressure (BEP) ratio of 20. Following native oxide desorption, a 100-nm $\mathrm{In}_{0.52} \mathrm{Al}_{0.48} \mathrm{As}$ buffer layer was first grown at $460^{\circ} \mathrm{C}$. Then, the substrate temperature was lowered to $210^{\circ} \mathrm{C}$. After the substrate temperature is stable, the $100-\mathrm{nm}\left(\mathrm{In}_{0.52} \mathrm{Al}_{0.48}\right)_{0.91} \mathrm{Mn}_{0.09} \mathrm{As}$ epilayer was subsequently grown. The growth rates of $\mathrm{In}_{0.52} \mathrm{Al}_{0.48} \mathrm{As}$ and $\left(\mathrm{In}_{0.52} \mathrm{Al}_{0.48}\right)_{0.91} \mathrm{Mn}_{0.09} \mathrm{As}$ were all about $0.3 \mu \mathrm{m} / \mathrm{h}$. The growth was monitored in situ with the reflection high energy electron diffraction (RHEED), and a $(2 \times 4)$ pattern was observed for the $\operatorname{In}_{0.52} \mathrm{Al}_{0.48} \mathrm{As}$ buffer layers, while it changed to $(1 \times \mathrm{n})$ during and after growth of the $\left(\mathrm{In}_{0.52} \mathrm{Al}_{0.48}\right)_{0.91} \mathrm{Mn}_{0.09} \mathrm{As}$ epilayer. After growth, the wafer was cleaved into pieces for various characterizations. The post-growth annealing was performed in air at $210{ }^{\circ} \mathrm{C}$, $230{ }^{\circ} \mathrm{C}, 250^{\circ} \mathrm{C}, 270^{\circ} \mathrm{C}$, or $290^{\circ} \mathrm{C}$ for $2 \mathrm{~h}$. A0, A1, A2, A3, $\mathrm{A} 4$, and $\mathrm{A} 5$ denote the as-grown and corresponding annealed samples at $210{ }^{\circ} \mathrm{C}, 230{ }^{\circ} \mathrm{C}, 250{ }^{\circ} \mathrm{C}, 270{ }^{\circ} \mathrm{C}$, and $290^{\circ} \mathrm{C}$, respectively. The Mn concentration was determined by electron microprobe analysis (EMPA), and the crystalline structure and microstructure of $\left(\mathrm{In}_{0.52} \mathrm{Al}_{0.48}\right)_{0.91} \mathrm{Mn}_{0.09} \mathrm{As}$ epilayers were examined using double-crystal X-ray diffraction (DXRD) and transmission electron microscopy (TEM), respectively. Cross-sectional samples parallel to (011) planes for TEM observation were prepared by mechanical thinning and Ar-ion milling. Magnetic properties were measured by a Quantum Design superconducting quantum interference device (SQUID) magnetometer.

\section{RESULTS AND DISCUSSION}

The microstructure and interface quality of the $\left(\mathrm{In}_{0.52} \mathrm{Al}_{0.48}\right)_{0.91} \mathrm{Mn}_{0.09} \mathrm{As}$ as-grown and annealed samples were examined by cross-sectional TEM. It was noted that all of the as-grown and annealed samples were of single crystal with zinc-blend structure and had high-quality interface between the (In, Al, Mn)As epilayer and $\operatorname{In}_{0.52} \mathrm{Al}_{0.48} \mathrm{As}$ buffer layer. As an example, the bright-field image and lattice image of 

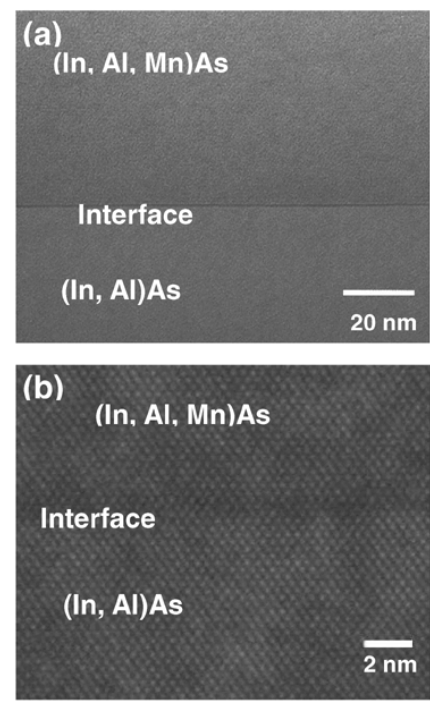

Fig. 1. Microstructure analysis of the $250^{\circ} \mathrm{C}$ annealed sample. (a) Bright field TEM image. (b) Lattice image.

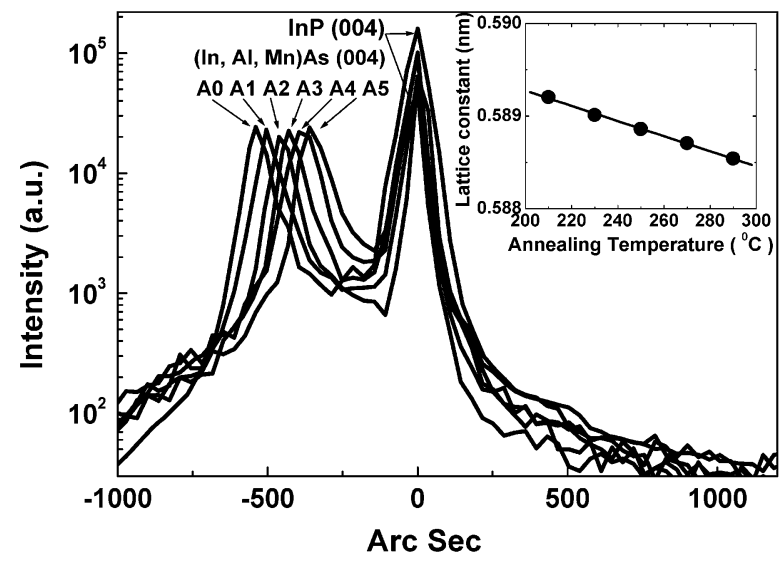

Fig. 2. (004) double-crystal X-ray rocking curves obtained from the as-grown sample A0 and annealed samples A1, A2, A3, A4, and A5. The inset plots the lattice constant of $\left(\mathrm{In}_{0.52} \mathrm{Al}_{0.48}\right)_{0.91} \mathrm{Mn}_{0.09} \mathrm{As}$ as a function of the annealing temperature.

the $250^{\circ} \mathrm{C}$-annealed sample are shown in Fig. 1(a) and (b). From the TEM observations, it can be roughly concluded that the present low-temperature annealing has little influence on the microstructure of $\left(\mathrm{In}_{0.52} \mathrm{Al}_{0.48}\right)_{0.91} \mathrm{Mn}_{0.09} \mathrm{As}$ epilayer and the interface quality between the $\left(\mathrm{In}_{0.52} \mathrm{Al}_{0.48}\right)_{0.91} \mathrm{Mn}_{0.09} \mathrm{As}$ epilayer and $\mathrm{In}_{0.52} \mathrm{Al}_{0.48} \mathrm{As}$ buffer layer. There is no trace of the formation of any other second phases in the $\left(\mathrm{In}_{0.52} \mathrm{Al}_{0.48}\right)_{0.91} \mathrm{Mn}_{0.09} \mathrm{As}$ matrix, either.

The variation in the lattice constant of the as-grown and all annealed $\left(\mathrm{In}_{0.52} \mathrm{Al}_{0.48}\right)_{0.91} \mathrm{Mn}_{0.09} \mathrm{As}$ epilayers was determined using DXRD at room temperature, and the resultant X-ray diffraction profiles are shown in Fig. 2. For all samples, clear diffraction peaks from the $\left(\operatorname{In}_{0.52} \mathrm{Al}_{0.48}\right)_{0.91} \mathrm{Mn}_{0.09} \mathrm{As}$ (004) reflections were observed, which suggests that single crystalline $\left(\mathrm{In}_{0.52} \mathrm{Al}_{0.48}\right)_{0.91} \mathrm{Mn}_{0.09} \mathrm{As}$ with zinc-blend structure has been epitaxially grown on InP. No evident (004) reflections of the $\mathrm{In}_{0.52} \mathrm{Al}_{0.48}$ As buffers were observed, implying that the buffers are almost lattice-matched with the InP substrates. In addition, the peak separation between the $\left(\operatorname{In}_{0.52} \mathrm{Al}_{0.48}\right)_{0.91} \mathrm{Mn}_{0.09} \mathrm{As}$

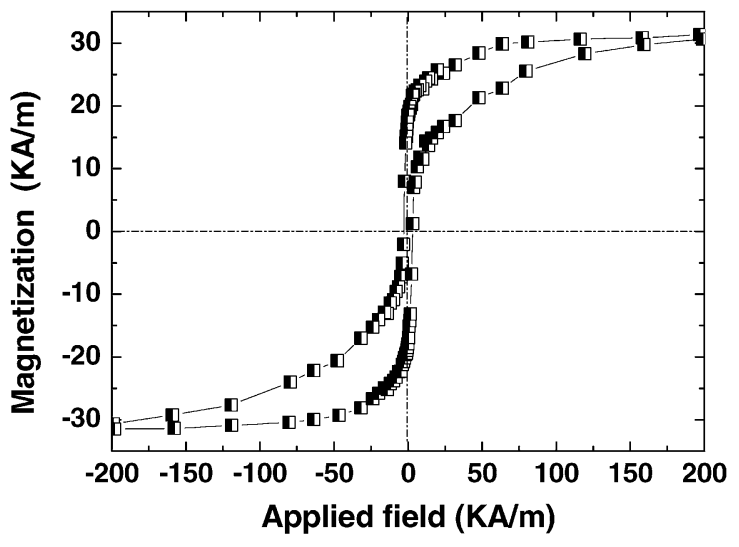

Fig. 3. Magnetization hysterisis loop (field in plane) at $5 \mathrm{~K}$ for the annealed sample A3.

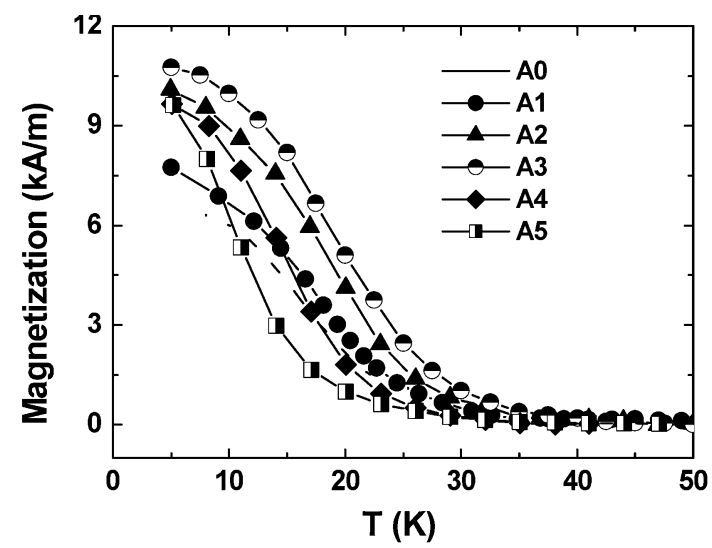

Fig. 4. Temperature dependence of the magnetization for the as-grown sample A0 and annealed samples A1, A2, A3, A4, and A5 in a small in-plane applied magnetic field $(H=100 \mathrm{Oe})$.

and $\mathrm{InP}$ reflections is found to decrease with increasing annealing temperature. This indicates that the low-temperature annealing indeed has a strong effect on the lattice constant of the $\left(\mathrm{In}_{0.52} \mathrm{Al}_{0.48}\right)_{0.91} \mathrm{Mn}_{0.09} \mathrm{As}$ epilayer. The inset in Fig. 2 plots the lattice constants of $\left(\operatorname{In}_{0.52} \mathrm{Al}_{0.48}\right)_{0.91} \mathrm{Mn}_{0.09} \mathrm{As}$ as a function of the annealing temperature. It clearly shows that the lattice constant of $\left(\operatorname{In}_{0.52} \mathrm{Al}_{0.48}\right)_{0.91} \mathrm{Mn}_{0.09}$ As linearly decreases with increasing annealing temperature, from $0.5894 \mathrm{~nm}$ for the as-grown sample to $0.5885 \mathrm{~nm}$ for the $290^{\circ} \mathrm{C}$ annealed sample. The reduction in the lattice constant of the present $\left(\mathrm{In}_{0.52} \mathrm{Al}_{0.48}\right)_{0.91} \mathrm{Mn}_{0.09} \mathrm{As}$ induced by low-temperature annealing has similar trend of that of $(\mathrm{Ga}, \mathrm{Mn}) \mathrm{As}$ [11], [12].

The as-grown and all annealed $\left(\operatorname{In}_{0.52} \mathrm{Al}_{0.48}\right)_{0.91} \mathrm{Mn}_{0.09} \mathrm{As}$ epilayers exhibit a ferromagnetic state at $5 \mathrm{~K}$ as confirmed by the $M-H$ curves. All $M-H$ curves were very similar in shape. As an example, the $M-H$ curve of sample A3 is shown in Fig. 3, which suggests a ferromagnetic hysteresis behavior.

The field-cooling temperature dependence of magnetization ( $M-T$ curves) of the as-grown and all annealed samples were measured in a small in-plane applied magnetic field $(H=100$ Oe), from which the Curie temperature, $T_{C}$, of each sample is determined. Fig. 4 shows the $M-T$ curves of samples A0, A1, A2, A3, A4, and A5, and the corresponding Curie temperatures are $29 \mathrm{~K}, 34 \mathrm{~K}, 38 \mathrm{~K}, 42 \mathrm{~K}, 26 \mathrm{~K}$, and $23 \mathrm{~K}$, respectively. Two regimes of the temperature dependence of Curie temperatures of 
$\left(\mathrm{In}_{0.52} \mathrm{Al}_{0.48}\right)_{0.91} \mathrm{Mn}_{0.09} \mathrm{As}$ is founded; the $T_{\mathrm{C}}$ increases almost linearly with increasing annealing temperature up to $250{ }^{\circ} \mathrm{C}$, and then decreases abruptly when the annealing temperature is further increased to $270^{\circ} \mathrm{C}$ and $290^{\circ} \mathrm{C}$. It should be noted that the Curie temperatures of $\left(\mathrm{In}_{0.52} \mathrm{Al}_{0.48}\right)_{0.91} \mathrm{Mn}_{0.09}$ As are comparable to those of (In, Mn)As, but are quite less than those of (Ga, Mn)As and (In, Ga, Mn)As.

\section{CONCLUSION}

The effects of low-temperature annealing on the microstructure, lattice constant, and magnetic properties of $\left(\mathrm{In}_{0.52} \mathrm{Al}_{0.48}\right)_{0.91} \mathrm{Mn}_{0.09} \mathrm{As}$ were investigated. The results show that the low-temperature annealing has little influence on the crystalline structure and interface quality of $\left(\mathrm{In}_{0.52} \mathrm{Al}_{0.48}\right)_{0.91} \mathrm{Mn}_{0.09} \mathrm{As}$, and the as-grown and all annealed $\left(\mathrm{In}_{0.52} \mathrm{Al}_{0.48}\right)_{0.91} \mathrm{Mn}_{0.09} \mathrm{As}$ epilayers exhibit nearly identical $M-H$ curves at $5 \mathrm{~K}$. In contrast, both the lattice constant and Curie temperature of $\left(\mathrm{In}_{0.52} \mathrm{Al}_{0.48}\right)_{0.91} \mathrm{Mn}_{0.09} \mathrm{As}$ are found to be strongly dependent on the annealing temperature. The lattice constant decreases linearly with increasing annealing temperature; while the Curie temperature increases almost linearly with increasing annealing temperature up to $250{ }^{\circ} \mathrm{C}$, and then decrease abruptly upon further annealed at higher temperatures of $270{ }^{\circ} \mathrm{C}$ and $290{ }^{\circ} \mathrm{C}$.

\section{ACKNOWLEDGMENT}

This work was supported by the National Science Council, R.O.C., under Contract NSC 92-2112-M-007-032 and Contract NSC 92-2120-M-007-006.

\section{REFERENCES}

[1] H. Munekata, H. Ohno, S. von Molnár, A. Segmüller, L. L. Chang, and L. Esaki, Phys. Rev. Lett., vol. 63, p. 1849, 1989.

[2] H. Ohno et al., Appl. Phys. Lett., vol. 69, p. 363, 1996.

[3] H. Ohno, Science, vol. 281, p. 951, 1998.

[4] Handbook of Magnetic Materials, vol. 14, K. H. J. Buschow, Ed., Amsterdam, North-Holland, 2002, pp. 1-87.

[5] T. Dietl, H. Ohno, F. Matsukura, J. Cibert, and D. Ferrand, Science, vol. 287, p. 1019, 2000.

[6] T. Hayashi, Y. Hashimoto, S. Katsumoto, and Y. Iye, Appl. Phys. Lett., vol. 78, p. 1691, 2001.

[7] T. Slupinski, H. Munekata, and A. Oiwa, J. Supercond., vol. 16, p. 45, 2003.

[8] S. Ohya, H. Yamaguchi, and M. Tanaka, J. Supercond., vol. 16, p. 139, 2003.

[9] T. Slupinski, H. Munekata, and A. Oiwa, Appl. Phys. Lett., vol. 80, p. $1592,2002$.

[10] S. Ohya, H. Kobayashi, and M. Tanaka, Appl. Phys. Lett., vol. 83, p. 2175, 2003.

[11] S. J. Potashnik, K. C. Ku, S. H. Chun, J. J. Berry, N. Samarth, and P. Schiffer, Appl. Phys. Lett., vol. 79, p. 1495, 2001.

[12] M. B. Stone, K. C. Ku, S. J. Potashnik, B. L. Sheu, N. Samarth, and P. Schiffer, Appl. Phys. Lett., vol. 83, p. 4568, 2003.

[13] K. C. Ku et al., Appl. Phys. Lett., vol. 82, p. 2302, 2003.

[14] D. Chiba, K. Takamura, F. Matsukura, and H. Ohno, Appl. Phys. Lett., vol. 82, p. 3020, 2003.

[15] K. W. Edmonds et al., Phys. Rev. Lett., vol. 92, p. 037 201, 2004.

[16] H. Ohno, H. Munekata, T. Penney, S. von Molnár, and L. L. Chang, Phys. Rev. Lett., vol. 68, p. 2664, 1992.

[17] G. A. Prinz, Science, vol. 282, p. 1660, 1998.

Manuscript received February 6, 2005 